\title{
Baseline Levels of Polybrominated Diphenyl Ethers (PBDEs) in Water and Sediment from River Benue, North Central Nigeria
}

\author{
Sylvester M.Tongu ${ }^{1 *}$, Rufus Sha'Ato ${ }^{1}$, Jonathan O. Okonkwo ${ }^{2}$, Olubiyi I. Olukunle ${ }^{3}$, Ishaq S. Eneji ${ }^{1}$, Terrumun A. \\ Tor-Anyiin $^{1}$ \\ ${ }^{1}$ Department of Chemistry, Federal University of Agriculture, Makurdi, MB 2373 Makurdi, Benue State, Nigeria \\ ${ }^{2}$ Department of Environmental, Water and Earth Sciences, Tshwane University of Technology, Pretoria 0001, South Africa \\ ${ }^{3}$ School of Public and Environmental Affairs, Indiana University, 702 N Walnut Grove Avenue, Bloomington, IN 47405, USA \\ *tongusyl@gmail.com
}

\begin{abstract}
Polybrominated diphenyl ethers (PBDEs) have been recognised as persistent organic pollutants (POPs) and are also among chemicals classified as endocrine-disrupting compounds (EDCs) which interfere with the endocrine system and disrupt the physiological function of hormones in animals and humans alike. This study determined the concentrations of six PBDE congeners (BDE 47, BDE 99, BDE 100, BDE 153, BDE 154 and BDE 183) in water and sediment samples from River Benue, in the Makurdi Metropolitan Area in North Central Nigeria using gas chromatogragh - mass spectrometer. These congeners are components of the penta- and octaBDE formulations that have been banned by the European Union. The samples were collected from the River, bimonthly, for one year across dry and wet seasons. All the congeners considered were found to be present in both water and sediment. The levels of $\Sigma_{6}$ PBDEs in water ranged from $0.02-0.11 \mathrm{ngL}^{-1}$ during dry season and $0.10-0.76 \mathrm{ngL}^{-1}$ during wet season while the concentrations in sediment during dry and wet seasons ranged from $4.65-26.74$ ngg $^{-1}$ and $4.40-17.15$ ngg $^{-1}$ respectively. The $^{-10}$ percentage recoveries from solid phase and Soxhlet extractions ranged from $68-111 \%$ and $71-109 \%$ respectively. It was concluded that the presence of all the congeners in both water and sediment coupled with their established environmental persistence and bioaccumulation posed a pollution risk to the river which requires further monitoring and preventive measures to be taken.
\end{abstract}

Keywords- Gas chromatograph - mass spectrometer; polybrominated diphenyl ethers; sediment; river water; Nigeria

\section{INTRODUCTION}

PBDEs are brominated compounds containing a central diphenyl ether structure surrounded by 1 to 10 bromine atoms, which belong to a class of compound known as brominated flame retardants [1]. In general, brominated flame retardants (BFRs) are bromine-containing synthetic compounds that are reactively or additively incorporated widely into a variety of commercial products such as electrical and electronic equipment, plastics, textiles, polymers, furniture, paints, polyurethane foams, construction materials and many others to slow down or inhibit the initial phase of a developing fire [2-4]. They were once rated as the largest market group of FRs because of their high-performance efficiency and low cost [5]. The use of these flame retardants is believed to have successfully reduced fire-related deaths, injuries, and property damage [6]. More than 75 different BFRs have been recognized commercially [7] and prior to the ban on PBDEs (general chemical structure Fig. 1) they were the most commonly used. Others that were commonly used are polybrominated biphenyls (PBBs), hexabromocyclododecanes (HBCDs), and tetrabromobisphenol A (TBBPA) [2,8].

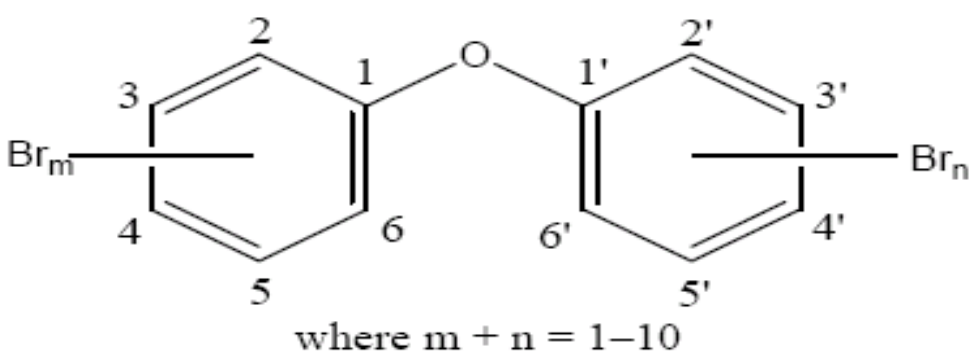

Fig. 1 General chemical structure of PBDEs showing numbering of the rings [1]

PBDEs were physically mixed into consumer products as additives hence they could be readily released into the local environment through volatilization under certain whether conditions [9]. Other ways through which PBDEs might have entered the environment include; emissions from manufacturing processes, recycling wastes and leachate from waste disposal sites 
$[2,10]$. Exposure to PBDEs above chronic oral reference doses (RfD) causes neurodevelopmental toxicity, weight loss, toxicity to the kidney, thyroid and liver and dermal disorders [10].

There are three major commercial formulations of PBDEs: the penta-BDE, octa-BDE and deca-BDE, which differ in their composition of BDE congeners [1,11]. PBDEs have been recognised as persistent organic pollutants (POPs) and are also among chemicals classified as endocrine-disrupting compounds (EDCs) which interfere with the endocrine system and disrupt the physiological function of hormones [7,10]. POPs are known to possess toxic properties, resist degradation, bioaccumulate and are transported, through air, water and migratory species, across international boundaries and deposited far from their place of release, where they accumulate in terrestrial and aquatic ecosystems [12].

The European Union, in 2004 banned the use of the penta- and octa-BDEs [3,6] and later, in 2008, also banned the decaBDEs. However, past use and environmental persistence could result in the continued presence of their constituent congeners in the environment [1].

Recent studies have confirmed the presence of PBDEs in different environmental matrices such as sediment, sewage, water, soil, vegetable, indoor and car dusts [3,8,13-16]. They have also been reported to be present bird eggs, aquatic mammals, fish and some sentinel aquatic organisms [17-20]. More worrisome are reports that confirm levels of PBDEs in human fluids and tissues such as breast milk, serum and adipose tissue [19,21].

The properties of PBDEs determine their distribution in environmental matrices. In general, PBDEs do not dissolve easily in water but bind strongly to soil or sediment particles, a property which reduces their mobility in soil, sediment and groundwater, but increases their mobility in the atmosphere, where they are attached to airborne particulate matter [10]. Hence their levels in aquatic environment are expected to be low in water samples due to their hydrophobic characteristics and high in sediment and particulate matter due to the adsorption properties of the compounds [22].

Few studies have reported on the levels of PBDEs in Nigeria but to the best of our knowledge none in River Benue. In 2013, researchers reported the total PBDE concentration of 0.11 to $23.33 \mathrm{mgkg}^{-1}$ in sediment of Lagos lagoon, South East Nigeria and asserted that the five PBDE congeners studied were present in all the studied locations [23]. In 2015, another study reported the average PBDE levels in e-waste polymers in Nigeria, based on analysis of 382 cathode ray tube (CRT) TV and computer casings to be $1.1 \%$ for TV and $0.13 \%$ for PC CRTs [24]. Furthermore, the concentrations of $\Sigma_{7}$ PBDEs in car and indoor dusts were reported in Central Nigeria in the range of 159 to $736 \mathrm{ngg}^{-1}$ dry weight and $57 \mathrm{ngg}^{-1}$ to $80 \mathrm{ngg}^{-1} \mathrm{respectively}^{-}$ [25-26].

This research was borne out of the concerns about PBDEs and the possibility of their presence in the water environment as they affect the River Benue in the Makurdi Metropolitan Area.

\section{MATERIALS AND METHODS}

\section{A. Chemicals}

$\mathrm{C}_{18}$-reversed phase Silica gel, dichloromethane, acetone, hexane, anhydrous sodium sulphate, copper powder and concentrated sulphuric acid were purchased from Bristol Scientific Company Limited, Lagos, Nigeria. PBDE standard solutions of BDE-47, -99, -100, -139, -153, -154, -139, -77, -118 and -183 were purchased from Wellingtoon Laboratories, Guelph Ontario, Canada. Nitrogen gas was purchased from Zayo-Sigma Chemicals Limited, Jos, Plateau State, Nigeria. All reagents were of GC/analytical grade.

\section{B. Study Area}

The River Benue has its source in the Cameroonian mountains. It covers an area of approximately 310,000 Ha and about $1.488 \mathrm{Km}$ in length with fertile flood plains on either bank. The River Benue flows through Makurdi, the capital city of Benue state, and confluences with River Niger at Lokoja the capital of Kogi state, Nigeria [27]. Makurdi is located on latitude $7^{\circ} 44^{\prime}$ $\mathrm{N}$ and longitude 832 ' E [28] with a population of about 292,645 inhabitants [29]. It has no good waste management system with resultant dumping of waste on the road side and in water channels. The city experiences two seasons; the wet season (April to October) and dry season (October to April). The major pollution sources to the river are municipal sewage, agricultural runoff, solid waste dumps and industrial waste. Fishing and sand dredging activities are common in the River Benue at Makurdi. Based on potential sources of pollution, three sites were selected for this study at Makurdi as shown in Fig. 2. Basic features around site 1 (R1) are companies producing alcoholic and non-alcoholic beverages, and a rice processing factory. Site 2 (R2) receives wastes from an abattoir and is located downstream a point of discharge of a stream that collects a variety of municipal wastes from a number of city drains. Farming is common around it. Site 3 (R3) is located behind Wadata market, Makurdi along the river course. The market generates a variety wastes including waste electrical and electronic equipment (WEEE) resulting from second hand electrical and electronic appliances commonly sold at the market. Heaps of refuse dump are commonly used as barricade against the rising water levels behind the market. In many cases varieties of waste are dumped directly into the river. 


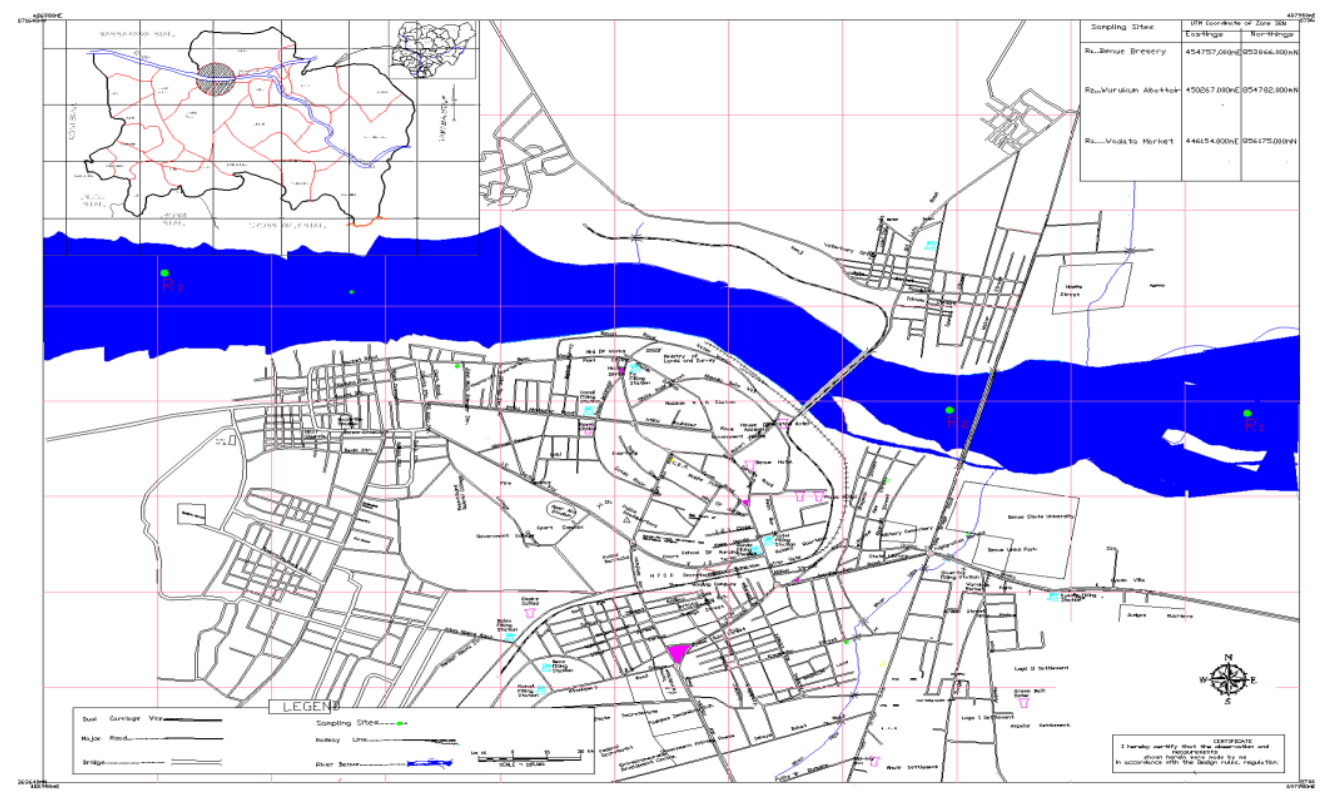

Fig. 2 Map of Makurdi Metropolis Showing Sampling Sites in River Benue

\section{Sample Collection}

Water and sediment samples were collected bimonthly from three (3) sampling sites within the study area (Fig. 2) covering three months in each season. Samples were taken at the same points within the sampling sites. Thoroughly-washed glassware, soaked overnight in dilute $\mathrm{HNO}_{3}$ solution and rinsed 3 times with distilled water and then with pure acetone was used.

\section{Water Sampling}

Sample bottles, $250 \mathrm{~mL}$ Winchester brown bottles, were used to collect water samples into $2.5 \mathrm{~L}$ Winchester brown bottles. Prior to use at each site, the bottles were first rinsed with the water samples. Then $250 \mathrm{~mL}$ bottle was dipped nine times ( $3 \mathrm{x} 2$ samples from the banks and 3 samples from the middle of the river) about $5 \mathrm{~cm}$ below the surface and allowed to fill before transferring the water into the $2.5 \mathrm{~L}$ bottle to make composite samples. An aliquot of $10 \mathrm{~mL}$ of concentrated sulphuric acid was added to the water samples for preservation and the bottles were thereafter tightly sealed. Samples were then transported immediately to the laboratory, where they were stored in a refrigerator at about $4{ }^{\circ} \mathrm{C}$. The samples were allowed to equilibrate at room temperature before they were extracted for analysis.

\section{E. Sediment Sampling}

Sediment samples were collected from about $0 \mathrm{~cm}$ to $5 \mathrm{~cm}$ below the benthic, from the same locations as water samples into wide-mouth $500 \mathrm{~mL}$ Winchester brown glass sampling bottles using stainless steel grab sampler. These glass bottles were closed immediately after sampling. The samples were then taken to the laboratory and kept in the refrigerator at about $4{ }^{\circ} \mathrm{C}$. Prior to extraction for analysis, the samples air dried at room temperature.

Extraction of both water and sediment samples was done according to [30] and [31] with some modifications.

\section{F. Solid Phase Extraction (SPE)}

Prior to extraction, water samples were spiked with $100 \mathrm{ng}{ }^{13} \mathrm{C}_{12}$ BDE-139 and -77. The samples were extracted using SPE column under gentle suction. Before use, the column was packed with glass wool at the bottom and $0.5 \mathrm{~g} \mathrm{C}_{18}$-reversed phase Silica gel on top of the wool, conditioned using $6 \mathrm{~mL}$ each of the eluting solvent and distilled water. The sample passed through it at the rate of $10 \mathrm{mLmin}^{-1}$, the column was dried under gentle suction for 15 mins and the compounds were eluted with $3 \times 2 \mathrm{~mL}$ of mixture of DCM/Hexane (4:1). Thereafter, eluates were passed through a column packed with $0.2 \mathrm{~g}$ anhydrous sodium sulphate, collected and reduced to incipient dryness under gentle stream of nitrogen. Before GC-MS analysis, the eluates were reconstituted in $500 \mu \mathrm{L}$ hexane containing $50 \mathrm{ng}$ BDE-118 internal standard and vortexed on a Lasec mixer (BV 100). The content was transferred into $1.5 \mathrm{~mL} \mathrm{GC}$ vial for analysis.

\section{G. Soxhlet Extraction}

The sediment extraction procedure was by Soxhlet method. The sediment was placed in a wash glass, air dried at ambient temperature for 5-6 days, ground with pestle and mortar, sieved through a $500 \mu \mathrm{m}$ pore mesh and $10 \mathrm{~g}$ of it thoroughly mixed with $20 \mathrm{~g}$ anhydrous sodium sulphate. It was then spiked with $150 \mathrm{ng}{ }^{13} \mathrm{C}_{12}$ BDE-139 and -77, left overnight to equilibrate before extraction with $200 \mathrm{~mL}$ hexane/acetone $(4: 1)$ in $500 \mathrm{~mL}$ round bottom flask at $55{ }^{0} \mathrm{C}$ for 16 hours. The extract was 
reduced to about $5 \mathrm{~mL}$ by recovery of solvent by condensation, $1 \mathrm{~g}$ copper powder was added to extract and swirled to remove sulphur. The extract was cleaned by SPE as described in the preparation of water samples before GC-MS analysis.

\section{H. GC-MS Analysis}

The water and sediment extracts were analysed using Shimadzu gas chromatograph model 2010 plus coupled with Shimadzu mass spectrometer model QP2010 mounted with auto sampler (AOC - 20i) and operated in electron ionization mode. The GC-MS conditions for analysis were as follows: column (DB $5-30 \mathrm{~m}$ x $0.25 \mathrm{~mm}$ ID x $0.1 \mu \mathrm{m}$ ), column oven temperature $-90{ }^{\circ} \mathrm{C}$, injection temperature $-280{ }^{\circ} \mathrm{C}$, injection mode - splitless, carrier gas - helium, flow control mode - linear velocity, column flow $-1.50 \mathrm{mLmin}^{-1}$, linear velocity $-44.4 \mathrm{~cm} / \mathrm{sec}$, pressure $-87.8 \mathrm{kpa}$. The operation was by selected ion monitoring (SIM). The oven temperature program was set at $90{ }^{\circ} \mathrm{C}(1 \mathrm{~min}), 30{ }^{\circ} \mathrm{C} / \mathrm{min}$ to $300{ }^{\circ} \mathrm{C}(5 \mathrm{~min})$ and $10{ }^{\circ} \mathrm{C} / \mathrm{min}$ to $310(10 \mathrm{~min})$. Carrier gas used was helium (purity $99.999 \%$ ) and set at a constant flow of $1.5 \mathrm{~mL}$ min-1. The injector, transfer line, and ion source temperatures were set at 290,300 , and $250{ }^{\circ} \mathrm{C}$, respectively. Identifications were made by monitoring the mass spectra of each congener at the elution retention time produced by the sample extracts in relation to the mass to charge ratio, retention time and the reference ion obtained from the standard solution.

\section{Quality Assurance}

Quality assurance measures used include collection of nine samples at each site and homogenizing same, duplicate analysis of the samples, prevention of samples from direct sunlight, transporting samples in cooler box, gentle and incipient drying of extracts, monitoring chromatographic conditions to check variations during analysis. Surrogate standards were used during extraction to ensure accuracy. External calibration of the GC-MS was performed using eight level calibration points and statistical correlation between analytical data was done using IBM SPSS Statistics 20.

\section{RESULTS AND DISCUSSION}

The recovery test of Soxhlet extraction of sediment showed recoveries of BDE 47(87 \%), BDE 99(71.2\%), BDE 100(111\%), BDE 153(84.5\%), BDE 154(68\%), BDE 183(89.3\%). The recoveries from river water were BDE 47(91 \%), BDE 99(72\%), BDE 100(98 \%), BDE 153(109\%), BDE 154(71\%), BDE 183(97.9\%). BDE 209, which is among the major PBDE congeners commonly reported in water and sediment in recent times, was not analysed for due to technical hitches.

The concentrations of six (6) PBDE congeners (BDE 47, BDE 99, BDE 100, BDE 153, BDE 154 and BDE 183) in River Benue during dry season are presented in the Figs. 3-6. The levels of each of the six PBDE congeners in water and sediment are shown in Figs. 3 and 5 respectively while total PBDEs ( $\Sigma_{6}$ PBDEs) which is the sum of the concentrations of six congeners per month at various sampling sites are shown in Figs. 4 and 6, for water and sediment respectively.

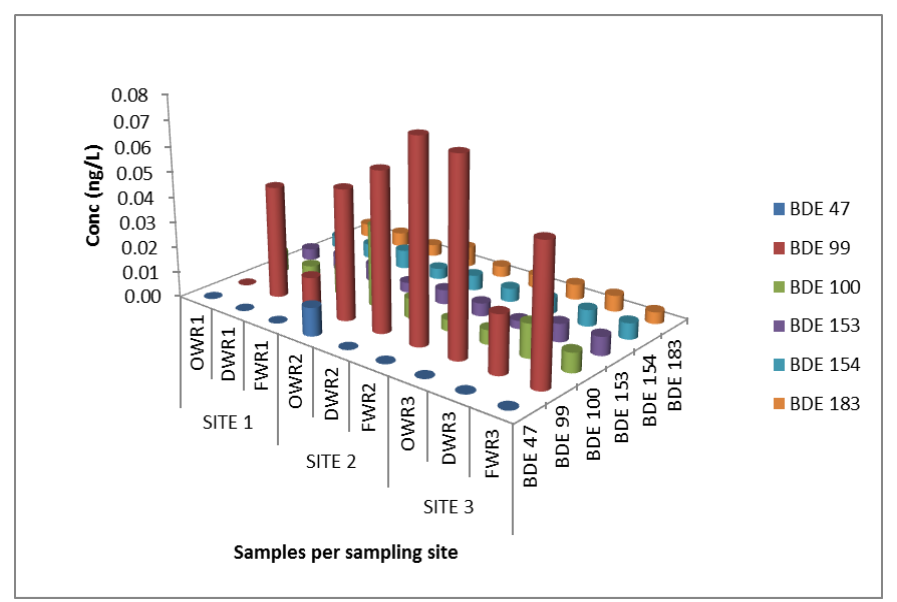

Fig. 3 Levels of PBDEs in water samples from River Benue during dry season; OWR1-OWR3 means October river water samples at sites 1 - 3; DWR1-; DWR3 means December river water samples at sites 1 - 3; FWR1-FWR3 means February river water samples at sites 1 - 3 


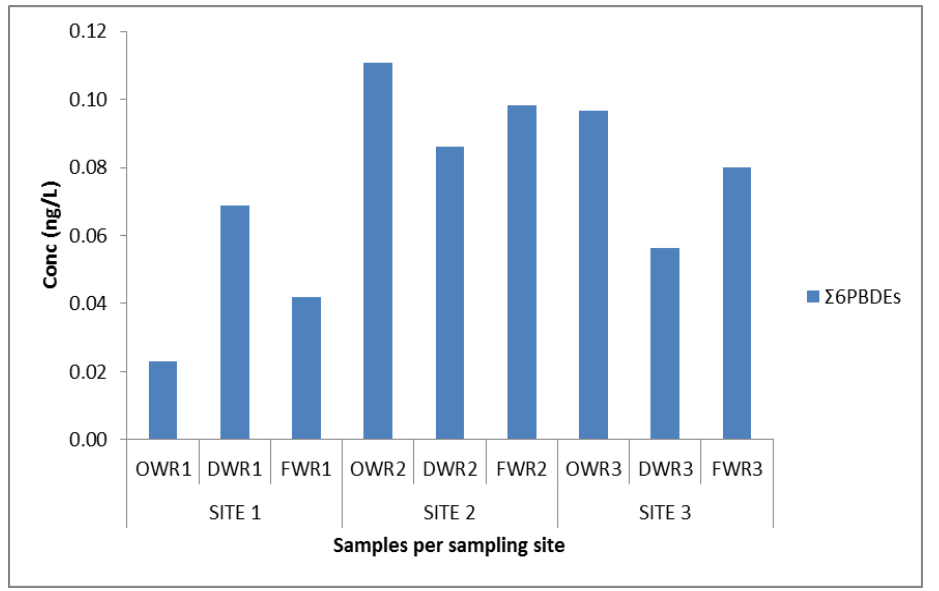

Fig. 4 ¿6PBDEs per month at various sampling sites in River Benue water during dry season

The concentrations of PBDEs in water during dry season ranged from ND (not detected) to 0.08 ngL $^{-1}$ (Fig. 3). For statistical purpose, zero was used in place of ND for data analysis. All the congeners analysed for were detected across all the sites except BDE 47 which was detected only once at site 2. BDE 99 maintained the highest concentration across all the sites during the season. The presence of the congeners poses a pollution threat since they are part of the congeners that make up the BDE formulations that have been banned by the EU due to their established environmental persistence and bioaccumulation. For example, congeners that make up the pentaBDE include BDE 99 (25 - 50\%), BDE 100 (6 - $10 \%)$ BDE 153 (3 - $5 \%$ ), BDE $154(2-4 \%)$ while those that make up the octaBDE include BDE 183 (40\%), BDE $153(5-10 \%)$, BDE $154(1-5 \%)$ (US EPA, 2010). The order of $\Sigma_{6}$ PBDEs concentrations across the sites was site $2>$ site $3>$ site 1 (Fig. 4). Since there is no point source of these pollutants into the river and the compounds are not produced within the study area, their presence could be attributed to PBDE containing substances that are introduced into the water environment. The amount of each congener will therefore depend on the percentage of its composition in the substance and the rate at which such substance enters the river. The environmental factors and properties of PBDEs can also affect levels of individual congener in an environment. For example, under favourable conditions, higher-brominated congeners undergo photochemical or biological debromination to lower brominated congeners.

A view of the $\Sigma_{6}$ PBDEs in water per month across the sampling sites during dry season showed the highest concentration of $0.11 \mathrm{ngL}^{-1}$ in October at site 2 and the least of $0.02 \mathrm{ngL}^{-1}$ in the same October at site 1 . The concentrations of total PBDEs in water per month at each site during the season are in the order of site 1: December > February > October; site 2: October > February $>$ December; site 3: October $>$ February $>$ December (Fig. 4). The order did not follow a definite pattern along the season.

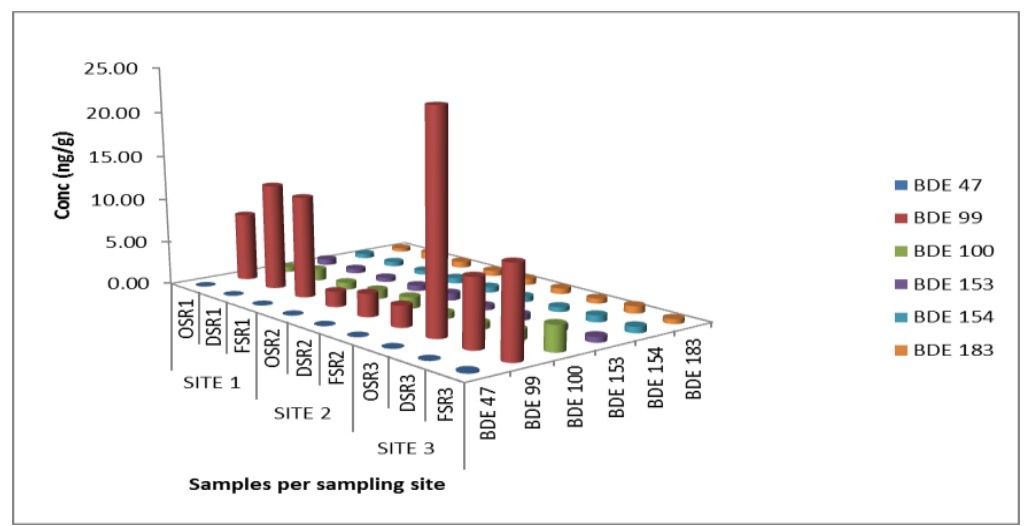

Fig. 5 Levels of PBDEs in sediment samples from River Benue during dry season; OSR1-OSR3 means October river sediment samples at sites 1 - 3; DSR1DSR3 means December river sediment samples at sites 1 - 3; FSR1-FSR3 means February river sediment samples at sites 1 - 3 


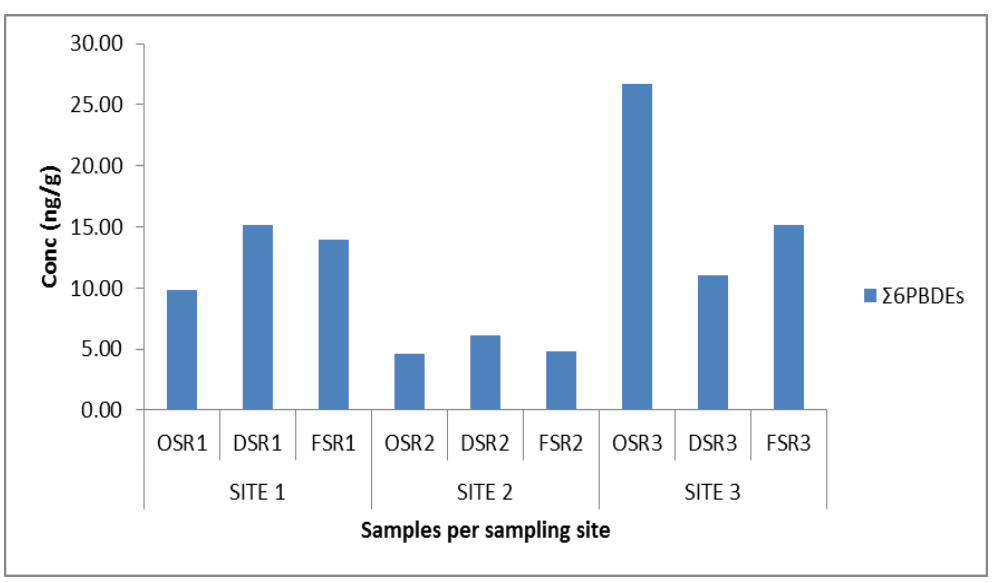

Fig. $6 \Sigma 6$ PBDEs per month at various sampling sites in River Benue sediment during dry season

The concentrations of PBDEs in sediment during dry season ranged from ND to $24.24 \mathrm{ngg}^{-1}$ (Fig. 5). The concentration of BDE 99 was consistently the highest across all the months and sites during the season while BDE 47 was detected only once at site 3. Next to highest in concentration was BDE 100 with $2.94 \mathrm{ngg}^{-1}$. The order of $\Sigma_{6} \mathrm{PBDEs}$ concentrations across the sites was site $3>$ site $1>$ site 2 (Fig. 6).

The $\Sigma_{6} \mathrm{PBDEs}$ in sediment per month across the sampling sites during the season was highest $\left(26.74\right.$ ngg- $\left.^{-1}\right)$ in October at site 3 and least $\left(4.65 \mathrm{ngg}^{-1}\right)$ in October at site 2. The concentrations of total PBDEs in sediment per month at each site during the season were in the order of site 1: December > February > October; site 2: December > February > October; site 3: October $>$ February $>$ December (Fig. 6). The order did not follow a definite pattern along the season. However, it replicated the trend of $\Sigma_{6}$ PBDEs in water obtained at same sites as the sediment except at site 2. Such replica trend showed that the level of the pollutants in water could be used to predict their levels in sediment. The deviation in the trend observed at site 2 can be attributed to human activities like sand excavation and activities of aquatic animals that can disturb the benthic of the river and promote the release of sediment bond pollutants at varying degrees.

The levels of each of the six PBDE congeners in water and sediment during wet season are shown in Figs. 7 and 9 respectively while Figs. 8 and 10 present the $\Sigma_{6}$ PBDEs per month at various sampling sites, during the season, are shown for water and sediment respectively.

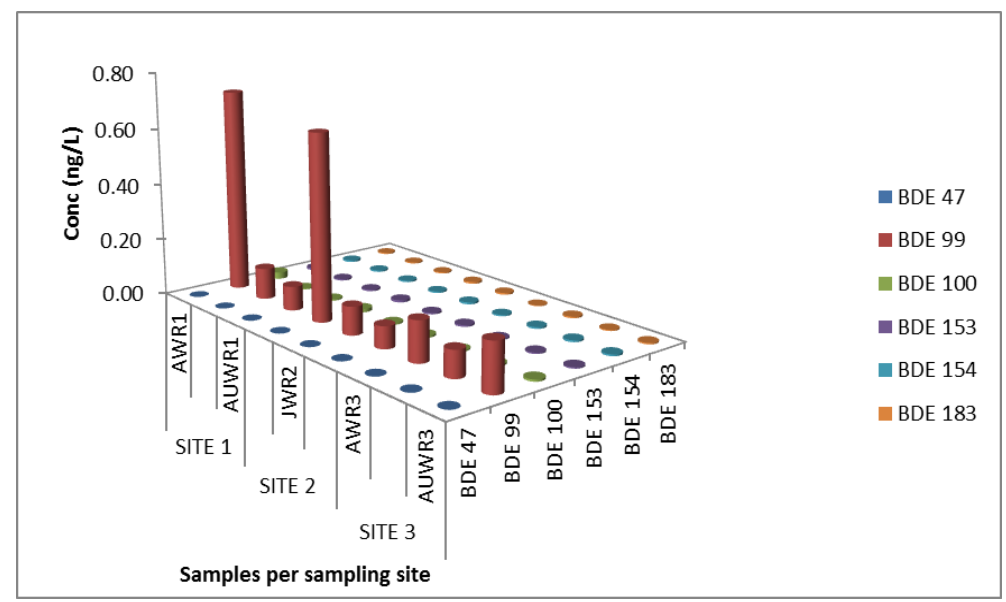

Fig. 7 Levels of PBDEs in water samples from River Benue during wet season; AWR1-AWR3 means April river water samples at sites 1 - 3; JWR1-JWR3 means June river water samples at sites 1 - 3; AUWR1-AUWR3 means August river water samples at sites 1 - 3 


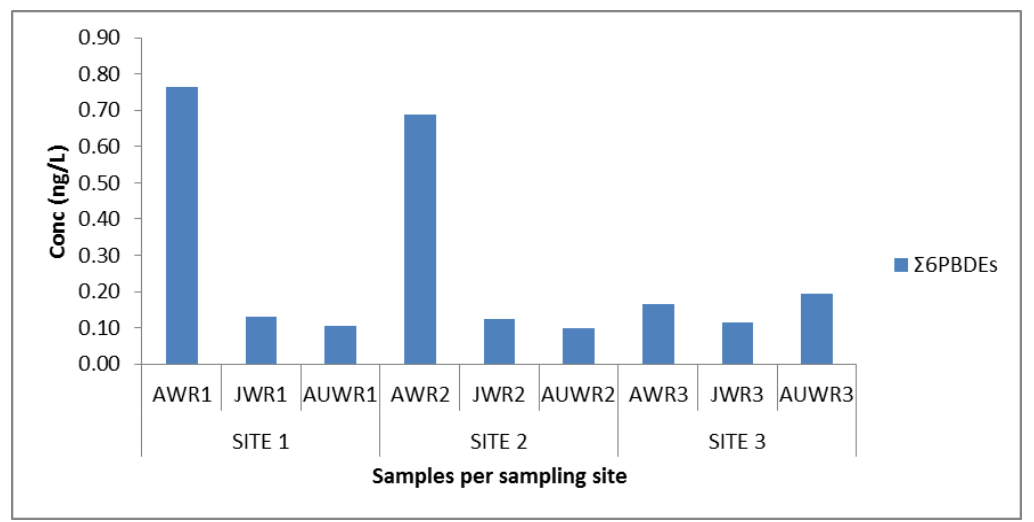

Fig. 8 ¿6PBDEs per month at various sampling sites in River Benue water during wet season

During wet season, the concentrations of PBDEs in water ranged from ND to $0.72 \mathrm{ngL}^{-1}$ (Fig. 7). With the exception of BDE 47, all the congeners analysed for were detected across all the sites and months with BDE 99 producing the highest concentrations in all cases. The order of $\Sigma_{6}$ PBDEs concentrations across the sites during the season was site $1>$ site $2>$ site 3 . This showed a decline in the concentration of $\Sigma_{6} \mathrm{PBDEs}$ downstream.

The levels of $\Sigma_{6} \mathrm{PBDEs}$ in water per month across the sampling sites during wet season were highest $\left(0.76 \mathrm{ngL}^{-1}\right)$ in April at site 1 and least $\left(0.10 \mathrm{ngL}^{-1}\right)$ in August at site 2. The total PBDEs in water per month at each site during the season is in the order of site 1: April > June > August; site 2: April > June > August; site 3: August > April > June (Fig. 8). Except at site 3 the concentrations showed a definite pattern of decreasing levels of PBDEs from the beginning of the wet season in April to the peak of the season in August. This trend could be attributed to dilution effect while the deviation from the trend at site 3 could be due to the variation in the amount of the pollutants entering the water per month.

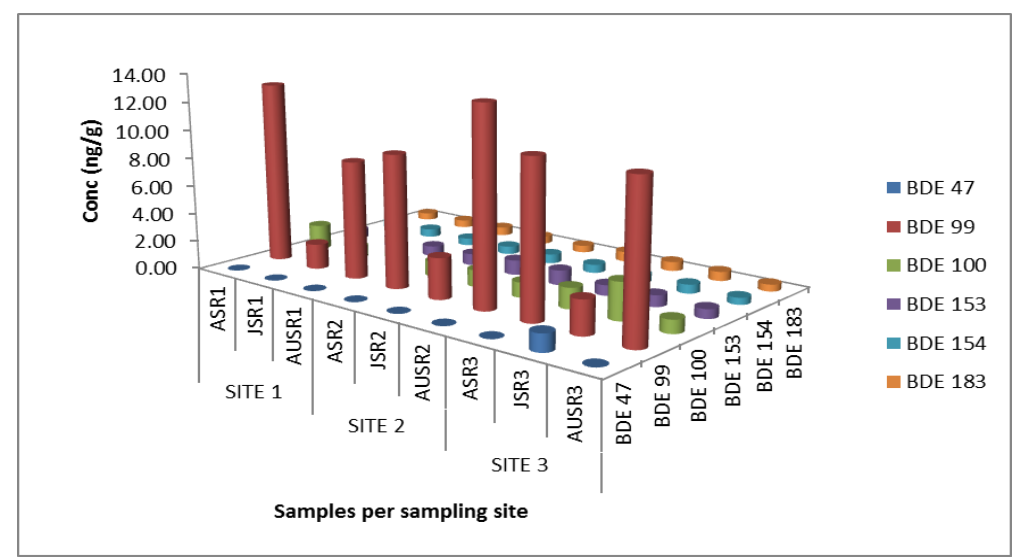

Fig. 9 Levels of PBDEs in sediment samples from River Benue during wet season; ASR1-ASR3 means April river sediment samples at sites 1 - 3; JSR1-JSR3 means June river sediment samples at sites 1-3; AUSR1-AUSR3 means August river sediment samples at sites 1 - 3

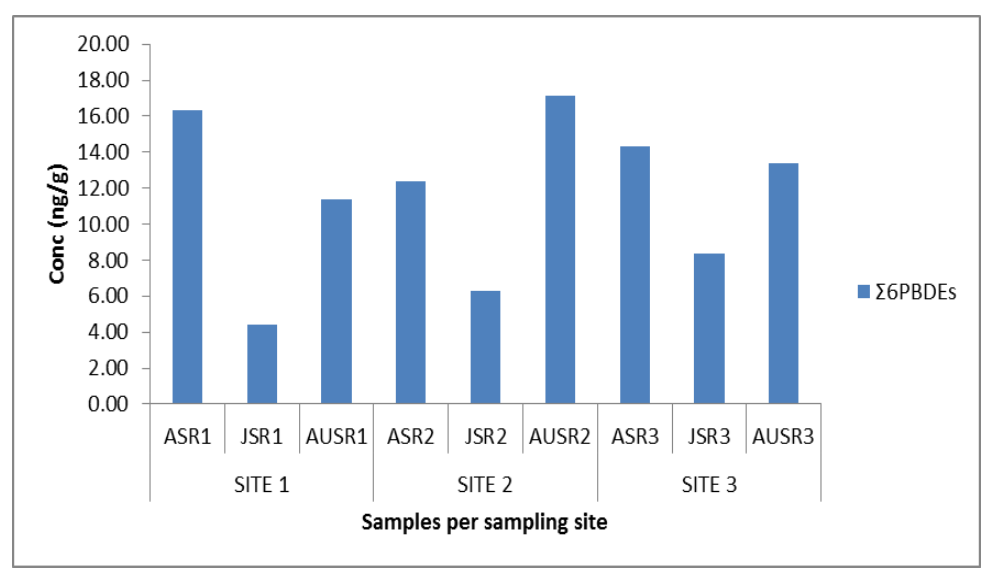

Fig. $10 \Sigma 6$ PBDEs per month at various sampling sites in River Benue sediment during wet season 
In sediment, the concentrations of PBDEs during wet season ranged from ND to 13.75 ngg $^{1}$ (Fig. 9). The concentration of BDE 99 continued to be highest in all the months and sites and BDE 47 was detected only once at site 3 . All the congeners analysed for were detected. The order of $\Sigma_{6}$ PBDEs concentrations across the sites was site $3>$ site $2>$ site 1 (Fig. 10). The order showed a decline in the concentrations of the pollutants downstream. The same Figure showed that the $\Sigma_{6}$ PBDEs in sediment per month across the sampling sites during the season was highest $\left(17.15 \mathrm{ngg}^{-1}\right)$ in August at site 2 and least (4.40 $\left.\mathrm{ngg}^{-1}\right)$ in June at same site 1 . The concentrations of total PBDEs in sediment per month at each site during the season were in the order of site 1: April > August > June; site 2: August > April > June; site 3: April > August > June (Fig. 10). The order in sites 1 and 3 were the same where the levels of $\Sigma_{6}$ PBDEs were highest in April, the beginning of wet season, declined in the middle of the season in June and rose again in August, the peak of the season. However, at site 1 the order changed with levels of $\Sigma_{6}$ PBDEs being highest in August, the peak of the wet season declining in June, the middle of the season and rising in April, the beginning of the season. Similarly, the order did not replicate the trend of $\Sigma_{6}$ PBDEs in water obtained at same sites as the sediment.

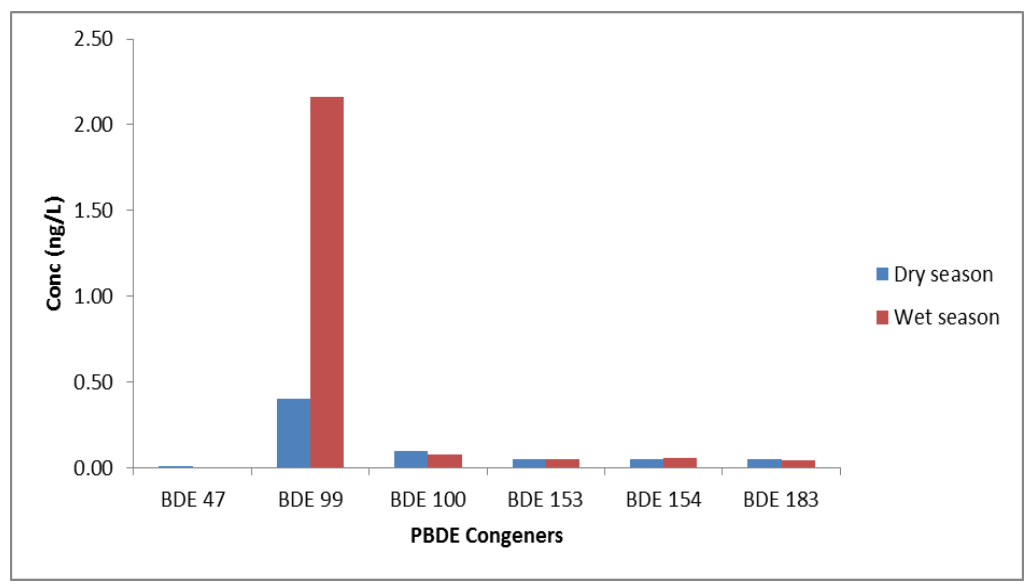

Fig. 11 Total congener of PBDEs in water from River Benue during dry and wet seasons

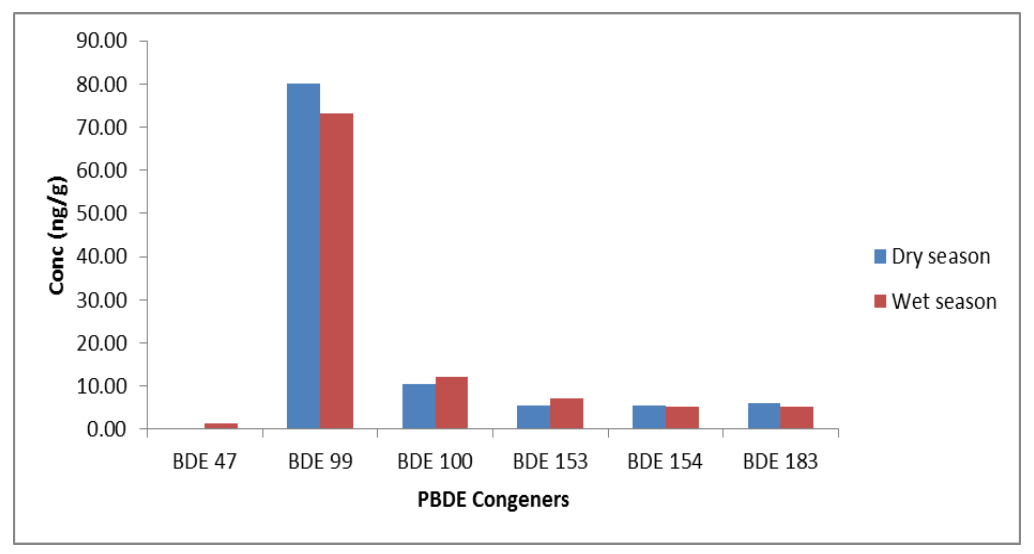

Fig. 12 Total congener of PBDEs in sediment from River Benue during dry and wet seasons

Comparisons between total congener (the sum of concentrations of a particular congener in a sample matrix) of PBDEs in water during dry and wet seasons (Fig. 11), and in sediment during dry and wet seasons (Fig. 12) are presented below. The chart comparisons showed that total congener PBDEs in water and sediment were not based on season. While the concentrations of total congener of some congeners were higher in the matrices during the dry season others were higher during the wet season. In water the total congener of BDE 47, BDE 100 and BDE 183 were higher in dry season than in the wet while the values of BDE 99, BDE 153 and BDE 154 were higher in the wet season than in the dry. In sediment the total congener of BDE 99, BDE 154 and BDE 183 were higher in the dry season than in the wet while BDE 47, BDE 100 and BDE 153 were higher in the wet season than in the dry. This observation established a trend in which total congeners that were higher in water in a particular season were lower in sediment in the same season and vice versa. However, total congener of BDE 153 and BDE 183 did not follow the trend but were higher both in water and sediment during the wet and dry seasons respectively.

The $\Sigma_{6} \mathrm{PBDEs}$ reported in this work ranged from $4.40-26.74 \mathrm{ngg}^{-1}$ in sediment dry weight (d.w.) and $0.02-0.76 \mathrm{ngL}{ }^{-1}$ in water. In another study, in Nigeria[23] the total concentrations of 8 PBDEs in sediments of lagoon has been reported in the range of 0.11 to $23.33 \mathrm{mg} / \mathrm{kg}$ while in sediment of Jukskei River, South Africa $\Sigma_{7}$ PBDEs of $0.92-6.76 \mathrm{ngg}^{-1} \mathrm{~d}$. w. was reported [3]. The levels of PBDEs in sediment obtained in the present study are higher than those reported in South Africa but 
less than the ones reported earlier in Nigeria. Similarly, $\Sigma_{8} \mathrm{PBDEs}$ of $0.31-84 \mathrm{ngL}^{-1}$ in major inflowing rivers of Lake Chaohu (China) [11] and $\Sigma_{8}$ PBDEs of $2.60-4.83 \mathrm{ngL}^{-1}$ in Diep River, South Africa [15] have been reported in literature. The result of the present study indicates lower levels of PBDEs in the water as compared to those reported in China and South Africa.

A Pearson correlation between $\Sigma_{6}$ PBDEs in water and in sediment (using IBM SPSS Statistics 20) across the sampling sites was significant at either $99 \%$ or $95 \%$. That implied a strong positive relationship between levels of PBDEs in water and in sediment.

\section{CONCLUSION}

All the seven PBDE congeners investigated were detected across the sampling sites with a strong positive Pearson correlation between $\Sigma_{6}$ PBDEs in water and in sediment except BDE 47 which was not detected at site 1 . BDE 99 was found to be dominant across all the sampling sites and periods. The presence of almost all the congeners across the sampling sites and periods coupled with their established environmental persistence and bioaccumulation pose a pollution risk which requires further monitoring and preventive measures to be taken. To the best of our knowledge, this is the first study that has established the levels of PBDEs in River Benue and the result can provide useful reference for further studies on PBDEs pollution and risk assessment in the river.

\section{ACKNOWLEDGMENT}

We acknowledge the funding support given to Tongu S. M. by University of Agriculture, Makurdi through the Needs Assessment Fund of the Federal Government of Nigeria as support to his doctoral research work, and the Tshwane University of Technology, Pretoria, Republic of South Africa for providing the laboratory facilities.

\section{REFERENCES}

[1] USEPA (Environmental Protection Agency), “An Exposure Assessment of Polybrominated Diphenyl Ethers,” EPA/600/R-08/086F. pp. $1-97,2010$.

[2] J. Xu, Z. Gao, Q. Xian, H. Yu, and J. Feng, "Levels and distribution of polybrominated dephenyl ethers (PBDEs) in the freshwater environment surrounding a PBDE manufacturing plant in China,” Environmental Pollution, vol. 157, pp. 1911-1916, 2009.

[3] O. Olukunle, J. Okonkwo, K. Kefeni, and M. Lupankwa, "Concentrations of Polybrominated Diphenyl Ethers in Sediments from Jukskei River, Gauteng, South Africa,” Bull Environ Contam Toxicol, vol. 88, pp. 461-466, 2012a.

[4] B. Kowalski and M. Mazur, "The Simultaneous Determination of Six Flame Retardants in Water Samples Using SPE Preconcentration and UHPLC-UV Method," Water Air Soil Pollution, vol. 225(3), pp. 1866-1874, 2014.

[5] O. Segev, A. Kushmaro, and A. Brenner, "Environmental Impact of Flame Retardants (Persistence and Biodegradability)," International Journal of Environmental Research and Public Health, vol. 6, pp. 478-491, 2009.

[6] Z. Sosa-Ferrera, C. Mahugo-Santana, and J. Santana-Rodriguez, "Analytical Methodologies for the Determination of Endocrine Disrupting Compounds in Biological and Environmental Samples,” BioMed Research International, 2013, 1-23, 2013.

[7] L. S. Birnbaum and D. F. Staskal, "Brominated Flame Retardants: Cause for Concern?" Environmental Health Perspectives, vol. 112(1), pp. 9-17, 2004.

[8] O. I. Olukunle, O. J. Okonkwo, K. K. Kefeni, and M. Lupankwa, "Determination of Brominated flame retardants in Jukskei River catchment area in Gauteng, South Africa," Water Science and Technology, vol. 65(4), pp. 743-749, $2012 \mathrm{~b}$.

[9] G. Zhao, Z. Wanga, M. H. Dong, K. Rao, J. Luo, D. Wanga, J. Zha, S. Huang, Y. Xu, and M. Ma, "PBBs, PBDEs, and PCBs levels in hair of residents around e-waste disassembly sites in Zhejiang Province, China, and their potential sources," Science Of The Total Environment, vol. 397, pp. 46-57, 2008.

[10] USEPA, "Technical Fact Sheet - Polybrominated Diphenyl Ethers (PBDEs) and Polybrominated Biphenyls (PBBs)," https://www.epa.gov/.../ffrrofactsheet contaminant perchlorate january2014 final 0.. Accessed 12/4/2017, 2014.

[11] X. Wang, B. Xi, S. Huo, L. Deng, H. Pan, X. Xia, Y. Zhang, Y. Ren, and H. Liu, "Polybrominated diphenyl ethers occurrence in major inflowing rivers of Lake Chaohu (China): Characteristics, potential sources and inputs to lake," Chemosphere, vol. 93(8), pp. 1624-163, 2013.

[12] Stockholm, "Stockholm Convention on Persistent Organic Pollutants," Treaty Series No. 22, 3p, 2005.

[13] D. Wang, Z. Cai, G. Jiang, A. Leung, M. H. Wong, and W. K. Wong, "Determination of polybrominated diphenyl ethers in soil and sediment from an electronic waste recycling facility," Chemosphere, vol. 60(6), pp. 810-816, 2005.

[14] M. Shin, M. L. Svoboda, and P. Falletta, "Microwave-assisted extraction (MAE) for the determination of polybrominated diphenylethers (PBDEs) in sewage sludge," Anal Bioanal Chem, vol. 387, pp. 2923-2929, 2007.

[15] A. P. Daso, O. S. Fatoki, and J. P. Odendaal, "Occurrence of polybrominated diphenyl ethers (PBDEs) and 2,2',4,4',5,5'hexabromobiphenyl (BB-153) in water samples from the Diep River, Cape Town, South Africa," Environ Sci Pollut Res, vol. 20, pp. 5168-5176, 2013.

[16] M. Oteng-Ababio, M. A. Chama, and E. F. Amankwaa, "Qualitative analysis of the presence of PBDE in ashes,soils and vegetables from Agbogbloshie e-wasterecycling site," Journal of Environmental Research and Management, vol. 5(4), pp. 071-080, 2014. 
[17] T. A. Verslycke, A. D. Vethaak, K. Arijs, and C. R. Janssen, "Flame retardants, surfactants and organotins in sediment and mysid shrimp of the Scheldt estuary (The Netherlands)," Environmental Pollution, vol. 136, pp. 19-31, 2004.

[18] D. Herzke, U. Berger, R. Kallenborn, T. Nygard, and W. Vetter, "Brominated flame retardants and other organobromines in Norwegian predatory bird eggs," Chemosphere, vol. 61, pp. 441-449, 2005.

[19] H. M. Stapleton, J. M. Keller, M. M. Schantz, J. R. Kucklick, S. D. Leigh, and S. A. Wise, "Determination of polybrominated diphenyl ethers in environmental standard reference materials," Anal Bioanal Chem, vol. 387, pp. 2365-2379, 2007.

[20] T. B. Chokwe, J. O. Okonkwo, L. L. Sibali, E. Krüger, H. du Preez, R. Hariram, and E. J. Ncube, "A simplified analytical procedure for simultaneous determination of alkylphenol ethoxylates and brominated flame retardants in fish tissue samples from vaal river, south Africa," American Journal of Analytical Chemistry, vol. 6, pp. 422-428, 2015.

[21] A. Sudaryanto, N. Kajiwara, S. Takahashi, H. Muawanah, and S. Tanabe, "Geographical distribution and accumulation features of PBDEs in human breast milk from Indonesia,” Environmental Pollution, vol. 151(1), pp. 130-138, 2008.

[22] Z. Katima, J. O. Okonkwo, and A. P. Daso, "A review of brominated flame retardants in the environment with emphasis on atmospheric levels, knowledge and information gaps in the African continent," Atmospheric Pollution Research, vol. XXX, pp. 1-14, 2017.

[23] G. O. Adewuyi and A. O. Adeleye, "Evaluation of polybrominated diphenyl ethers in sediment of Lagos Lagoon, Nigeria," African Journal of Environmental Science and Technology, vol. 7(7), pp. 686-693, 2013.

[24] O. Sindiku, J. Babayemi, O. Osibanjo, M. Schlummer, M. Schluep, A. Watson, and R. Weber, "Polybrominated diphenyl ethers listed as Stockholm Convention POPs, other brominated flame retardants and heavy metals in e-waste polymers in Nigeria," Environ Sci Pollut Res Int, vol. 22(19), 14489-501, 2015.

[25] O. I. Olukunle, O. J. Okonkwo, G. A. Wase, and R. Sha'Ato, "Polybrominated diphenyl ethers in car dust in Nigeria: Concentrations and implications for non-dietary human exposure," Microchemical Journal, vol. 123, pp. 99-104, $2015 \mathrm{a}$.

[26] O. I. Olukunle, O. J. Okonkwo, R. Sha'ato, and G. A. Wase, "Levels of polybrominated diphenylethers in indoor dust and human exposure estimates from Makurdi, Nigeria," Ecotoxicology and Environmental Safety, vol. 120, pp. 394-399, 2015 b.

[27] T. J. A. Akaahan, L. Leke, and I. S. Eneji, "Seasonal variation in hydro chemistry of River Benue at Makurdi, Benue State Nigeria," International Journal of Environment and Pollution Research, vol. 3(3), pp. 67-78, 2015.

[28] MAPLANDIA. "Makurdi Map - Satellite Images of Makurdi," www.maplandia.com/nigeria/benue/makurdi/makurdi. Accessed 2/1/16, 2016.

[29] R. A. Wuana, P. A. Aide, and I. N. Asegh, "Seasonal variation in bioavailability of some toxic metals - waste dumps of Makurdi North Central Nigeia," Journal of Bio diversity and Environmental science, vol. 2(11), pp. 7-17, 2012.

[30] USEPA, "Method 1614: Brominated Diphenyl Ethers in Water, Soil, Sediment, and Tissue by HRGC/HRMS," Office of Water Office of Science and Technology Engineering and Analysis Division (4303T) Washington, DC 20460 EPA-821-R-07-005, 2007.

[31] T. B. Chokwe, O. J. Okonkwo, L. L. Sibali, and S. M. Mporetji, "Occurrence and distribution pattern of alkylphenol ethoxylates and brominated flame retardants in sediment samples from Vaal River, South Africa," Bull Environ Contam Toxicol, vol. 97(3), pp. 353-8, 2016. 